\title{
Assessing the benefits of meshed operation of LV feeders with low carbon technologies
}

DOI:

10.1109/ISGT.2014.6816494

Link to publication record in Manchester Research Explorer

\section{Citation for published version (APA):}

Navarro-Espinosa, A., Ochoa, L. F., \& Randles, D. (2014). Assessing the benefits of meshed operation of LV feeders with low carbon technologies. In 2014 IEEE PES Innovative Smart Grid Technologies Conference, ISGT 2014/IEEE PES Innovative Smart Grid Technol. Conf., ISGT IEEE Computer Society . https://doi.org/10.1109/ISGT.2014.6816494

Published in:

2014 IEEE PES Innovative Smart Grid Technologies Conference, ISGT 2014|IEEE PES Innovative Smart Grid Technol. Conf., ISGT

\section{Citing this paper}

Please note that where the full-text provided on Manchester Research Explorer is the Author Accepted Manuscript or Proof version this may differ from the final Published version. If citing, it is advised that you check and use the publisher's definitive version.

\section{General rights}

Copyright and moral rights for the publications made accessible in the Research Explorer are retained by the authors and/or other copyright owners and it is a condition of accessing publications that users recognise and abide by the legal requirements associated with these rights.

\section{Takedown policy}

If you believe that this document breaches copyright please refer to the University of Manchester's Takedown Procedures [http://man.ac.uk/04Y6Bo] or contact uml.scholarlycommunications@manchester.ac.uk providing relevant details, so we can investigate your claim.

\section{OPEN ACCESS}




\section{Assessing the Benefits of Meshed Operation of LV Feeders with Low Carbon Technologies}

\author{
Alejandro Navarro-Espinosa and Luis F. Ochoa \\ The University of Manchester \\ Manchester, UK
}

\begin{abstract}
Significant penetrations of low carbon technologies in low voltage (LV) networks could result in voltage issues, thermal overloads of the lines, higher energy losses, etc. In this work, the meshed connection of $\mathrm{LV}$ feeders is investigated as one of the possible alternatives to minimise these impacts and, consequently, increase the corresponding hosting capacity. Two different technologies, photovoltaic panels (PV) and electric heat pumps (EHP) are studied for different penetration levels by using a real three-phase four-wire $L V$ network in the North West of England. Profiles of loads, PV and EHP have a granularity of 30 minutes. Energy losses, voltage problems and thermal loading are studied. A Monte Carlo approach is considered in order to cater for the random nature of some parameters such as the location and size of low carbon technologies. Results for the studied LV network clearly indicate that meshed operation can indeed increase its ability to host higher penetrations of PV and EHP.
\end{abstract}

Index Terms-- low voltage networks, low carbon technologies, meshed networks, ring connection.

\section{INTRODUCTION}

Penetrations of low carbon technologies such as photovoltaic panels, electric vehicles, micro combined heat and power and heat pumps, are likely to increase in the future, particularly affecting LV networks. These technologies might cause voltage issues (drop and/or rise, unbalance), thermal overload of the lines, more harmonics, higher energy losses, protection issues, etc. [1]. A complete description about the main distributed generation impacts is presented in [2].

Historically, most LV networks have been and are operated adopting a radial configuration. The main advantages of this are: lower network cost (since the conductor size can be reduced downstream the feeders, and a simpler, efficient protection scheme (generally overcurrent protection) [3]. Nonetheless, this configuration was not designed taking into account the presence of low carbon technologies.

In this paper, the meshed operation of LV feeders is investigated as one of the possible alternatives to increase the penetration of these technologies. This potential benefit has been recently explored in medium voltage (MV) with distributed generation (DG) [3]. Although the analysis considered losses, voltages, loading and short circuit levels, it was also limited to MV circuits. In addition, snapshot

This work has partly been funded by Electricity North West Limited (ENWL), UK, through the Ofgem's Low Carbon Networks Fund Tier 1 Project "LV Network Solutions”, 2011-2014.

\author{
Dan Randles \\ Electricity North West Limited \\ Warrington, UK
}

scenarios (i.e., combinations of load and generation levels) were simulated instead of a time series analysis. Also at MV level, three networks were studied in [4] looking at losses. In this case, the increase in the hosting capacity was investigated for only two DG locations (end and middle of a feeder). From a device perspective, the utilization of soft open points for looping MV networks was introduced in [5], and included the potential control of reactive and active flow between the connection points. The same control capabilities are observed and tested in the intelligence nodes presented in [6].

Here, the meshed operation approach is applied to a real LV network by using a time-series three-phase four-wire power flow. To analyse the corresponding effects under the presence of generation and new loads, different penetration levels of PV and EHP are considered. Energy losses, voltages and thermal impacts are taken as main parameters of performance. Furthermore, a Monte Carlo assessment is considered in order to cater for the random nature of some parameters such as the location and size of low carbon technologies [7].

This work is structured as follows: section II describes the input data including the network and load, PV and EHP profiles. Section III explains the methodology and presents the main results for the PV and EHP cases. Section IV extends the study with two sensitivity analyses. Finally, conclusions are drawn in section $\mathrm{V}$.

\section{INPUT DATA}

To assess the performance of the meshed operation of $\mathrm{LV}$ feeders, it is necessary to have the load/generation profiles and the networks to analyse. The time-series behaviour of loads (average summer and average winter) and the EHP consumption are obtained from [8]. The PV profile used in this paper is based on the same source. In fact, the average PV summer profile presented in [8] is scaled in order to have $3.04 \mathrm{~kW}$ of coincident generation; this value represents the average size for residential PV panel installed in UK during 2012 [9]. These profiles have a resolution of thirty minutes and are presented in Fig. 1. It is important to remark that those profiles are diversified; hence, all the customers will behave in the same way. This situation could distort the impacts, but still they are good enough to compare the effects considering radial and meshed operation. 


\section{Accepted Paper}

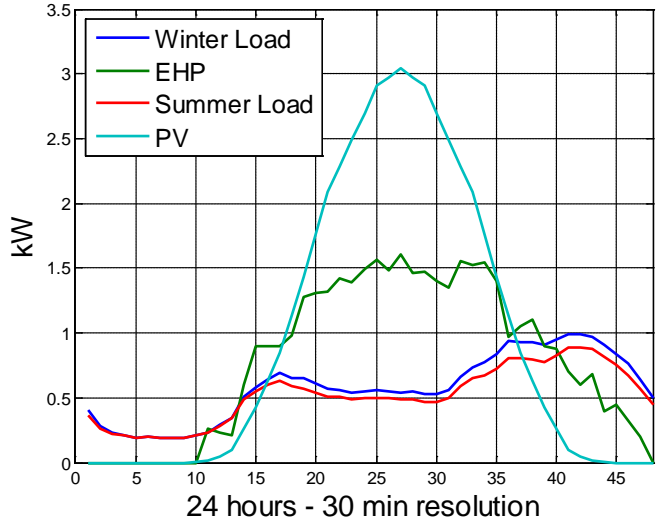

Figure 1. Diversified Profiles

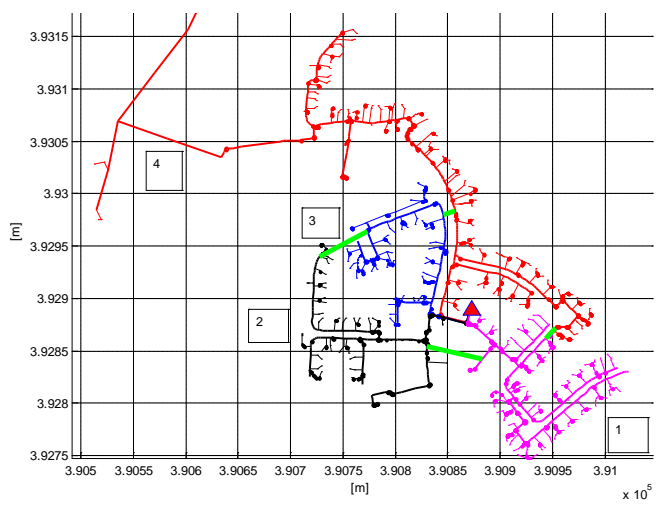

Figure 2. LV network topology.

In this work, the analysis is applied over one real network with 180 customers and $5.4 \mathrm{~km}$ of total length located in the North West of England. This network was fully modelled taking into account the network topology, conductor characteristics (three-phase four-wire), customer locations and phase connectivity. Fig. 2 depicts the four feeders and the feasible connections implemented in this work (green colour lines). Their feasibility is based on practical aspects such as distance between feeders and cable size.

\section{Methodology AND Results}

The methodology proposed to analyse the benefits of meshed operation is based on a Monte Carlo approach [7], analysing independently the impacts of PV and EHP devices. Thus, these technologies are randomly allocated to the customers in order to mimic different locational scenarios in the network. This is done for a given penetration level (based on the number of houses in the network) and repeated hundreds of times. For each time, a time-series three-phase four-wire power flow is solved by using OpenDSS [10]. Then, other penetration levels are explored, ranging from $0 \%$ to $100 \%$. For example, $20 \%$ of penetration level means that $20 \%$ of the houses in each feeder have the technology under analysis.

Since the same network will be tested for PV panels and EHP devices, the same voltage is set for both cases in order to facilitate the comparison between them. This value was selected to have similar headroom in term of voltage for both technologies. The nominal and maximum voltage according to the EN50160 [11] are $230 \mathrm{~V}$ and $253 \mathrm{~V}$ (i.e., +10\%), respectively. The best condition for EHP is the maximum voltage in order to mitigate possible voltage drop. For the PV panels this, however, would be $230 \mathrm{~V}$ to mitigate possible voltage rise. Consequently, a medium point between these values is selected: $241 \mathrm{~V}$. This value also happens to be aligned with UK practice for the corresponding off load tap changer.

The proposed methodology is applied for two cases: with and without meshed operation (i.e., radial operation). In particular, this paper analyses all the links shown in Fig. 2 connected simultaneously. To compare these scenarios, three metrics are developed. Firstly, the daily energy losses for the entire network are determined (aggregation of energy losses in each feeder). Then, the percentage of customers with voltage problems according to the EN50160 [11] are found. Finally, the utilization level (thermal loading) of the main segment of each feeder is analysed. Since a Monte Carlo approach is carried out, the average metric and the standard deviation is calculated for each penetration level.

\section{A. Generation Increase - PV case}

To understand the benefits with distributed generation, the PV penetration is analysed. Fig. 3 shows the reduction of losses after the meshed operation for each penetration level. In this figure, it is possible to observe the $U$ shape for distributed generation: the reduction of losses for small penetration levels and increase of losses for higher penetration levels. The effects on voltage are summarised in Fig. 4. Voltage problems appear at $40 \%$ and $60 \%$ of penetration in feeder 4 , with radial and meshed operation, respectively. For the same feeder, the thermal problems are delayed from $50 \%$ to $80 \%$ of penetration (Fig. 5). Therefore, the capacity to host residential PV generation in feeder 4 increased from $40 \%$ to $60 \%$.

To assess properly the benefits of meshed operation, the effects on the other three feeders are also analyzed. Table I shows for each feeder the penetration levels when voltage and thermal problems appear for the cases with and without meshed operation. This table also shows the hosting capacity, defined as the minimum penetration level when an issue appears (either voltage or thermal problems). Thus, it is possible to observe that the increase in the hosting capacity of feeder 4 implies a decrease for the rest of the feeders (due to thermal problems).

Assuming that the deployment rate of new residential PV panels is the same for each feeder, then the occurrence of the first problems in the network is delayed from $40 \%$ to $60 \%$ penetration after the meshed operation. Therefore, even if some feeders with initial good performance decrease their hosting capacity, the global hosting capacity increases.

\section{TABLE I. VARIATION IN HOSTING CAPACITY - PV CASE}

\begin{tabular}{|c|c|c|c|c|c|c|}
\multicolumn{3}{|c|}{ Without Meshed Operation } & \multicolumn{3}{c|}{ With Meshed Operation } \\
\hline Feeder & $\begin{array}{c}\text { Voltage } \\
\text { Problems } \\
{[\%]}\end{array}$ & $\begin{array}{c}\text { Thermal } \\
\text { Problems } \\
{[\%]}\end{array}$ & $\begin{array}{c}\text { Host } \\
\text { Capability } \\
{[\%]}\end{array}$ & $\begin{array}{c}\text { Voltage } \\
\text { Problems } \\
{[\%]}\end{array}$ & $\begin{array}{c}\text { Thermal } \\
\text { Problems } \\
{[\%]}\end{array}$ & $\begin{array}{c}\text { Host } \\
\text { Capability } \\
{[\%]}\end{array}$ \\
\hline 1 & 70 & 70 & 70 & 70 & 60 & 60 \\
\hline 2 & none & none & none & none & 100 & 100 \\
\hline 3 & none & none & none & none & 90 & 90 \\
\hline 4 & 40 & 50 & 40 & 60 & 80 & $\mathbf{6 0}$ \\
\hline
\end{tabular}




\section{Accepted Paper}

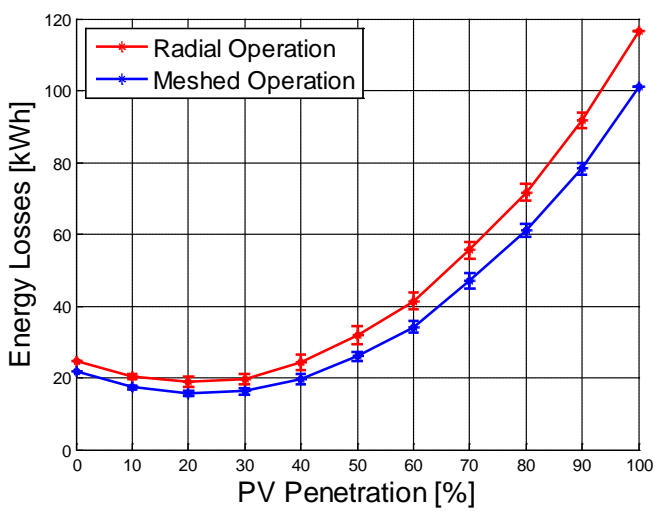

Figure 3. Energy Losses - PV case.

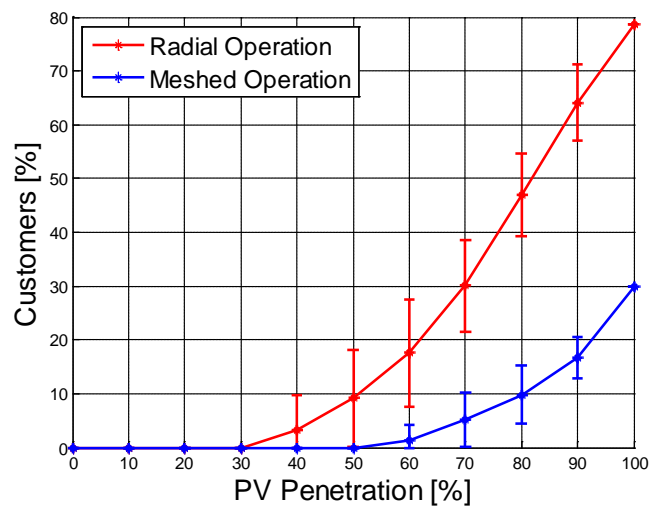

Figure 4. Voltage Problems Feeder 4- PV case.

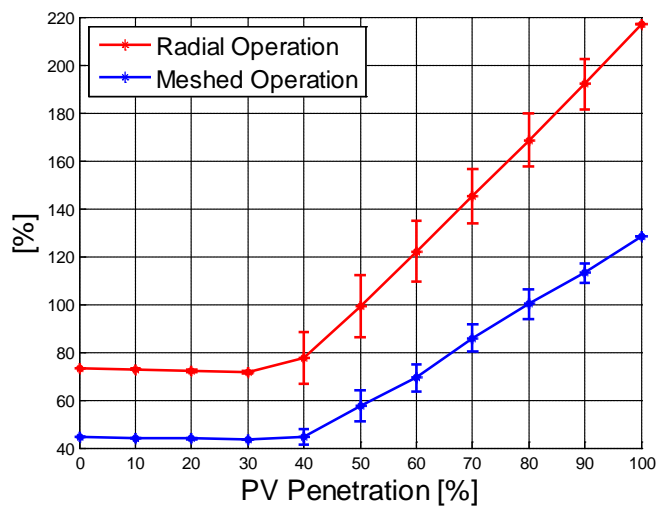

Figure 5. Thermal Problems Feeder 4 - PV case.

The above findings highlight that the meshed operation makes feeder 'share' the technical problems, improving the conditions of some of them (those more affected by PV) and decreasing the conditions of others. This leads to a delay in the overall occurrence of technical issues, i.e., higher penetrations of PV. Consequently, the meshed operation of LV feeders can be considered as a powerful short term tool to be used by distribution network operators (DNOs) to postpone the occurrence of network problems in the presence of residentialscale distributed generation.

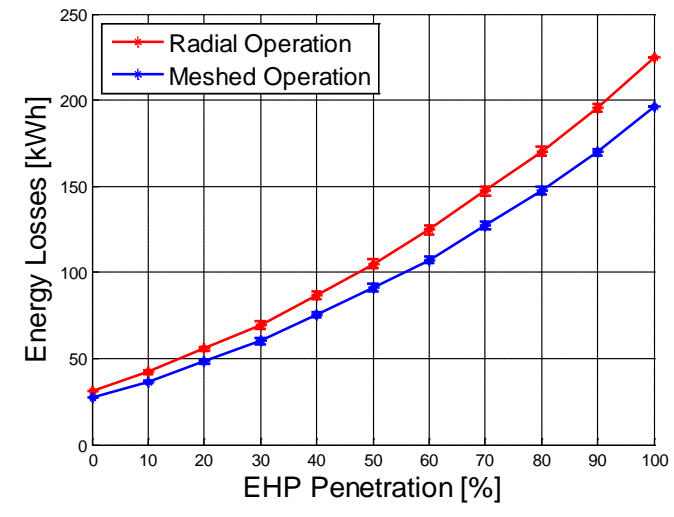

Figure 6. Energy Losses- EHP case.

\section{B. Consumption increase - EHP case}

To understand the benefits of meshed operation with additional load, different penetrations of EHP are analysed. The diversified profile used in this work is based on trial data [8]. Nevertheless, it is important to mention that more research is needed for the creation of realistic EHP profiles because it is possible to find some synthetic models [12] that behave differently to the one found in [8]. Therefore, the results presented here must be considered in this context.

From Fig. 6, it can be observed that the meshed operation of LV feeders produces a reduction of the daily energy losses for every penetration level. Additionally, the expected quadratic shape of losses (for both radial and meshed operations) can also be appreciated. On the other hand, Fig. 7 indicates the percentage of customers with voltage problems in feeder 4 . In this feeder, the voltage problems appear at $80 \%$ penetration when operated radially but none is found during meshed operation. This means that each house could have one EHP whilst also not being affected by severe voltage drops.

The evolution of the utilization factor in feeder 4 is presented in Fig. 8. It is possible to observe that the meshed operation defers the occurrence of thermal issues (overloading) in this particular feeder. Indeed, the capacity limit $(100 \%)$ is reached at $20 \%$ of penetration when radial and at $70 \%$ of penetration with meshed operation. Therefore, even if in terms voltages the penetration level could be $100 \%$ with meshed operation, due to the thermal constraints, the maximum penetration level is only $70 \%$. Consequently, the actual hosting capacities of feeder 4 are $20 \%$ and $70 \%$ of penetration, when the network is operated radially and meshed, respectively.

It is interesting to note that the hosting capacity of feeder 4 is driven by thermal problems for the EHP case and it is driven by voltage problems in the PV case. Also, it is worth mentioning that for this feeder, the problems start much earlier (20\%) in the EHP case than in the PV case (40\%). Thus, the hosting capacity of this feeder is different for different types of low carbon technologies. 


\section{Accepted Paper}

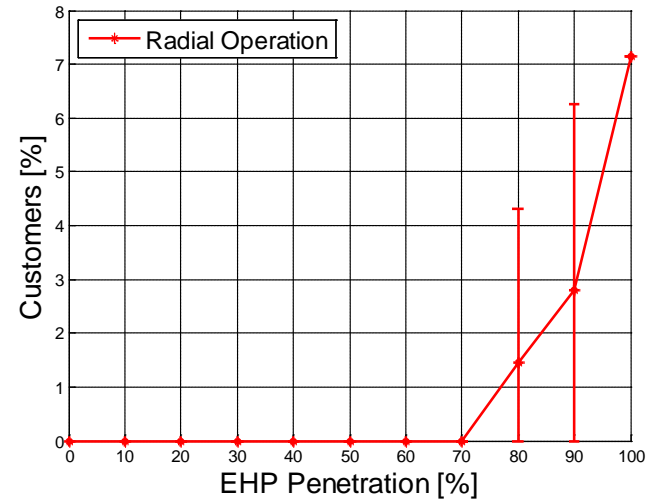

Figure 7. Voltage Problems Feeder 4 - EHP case.

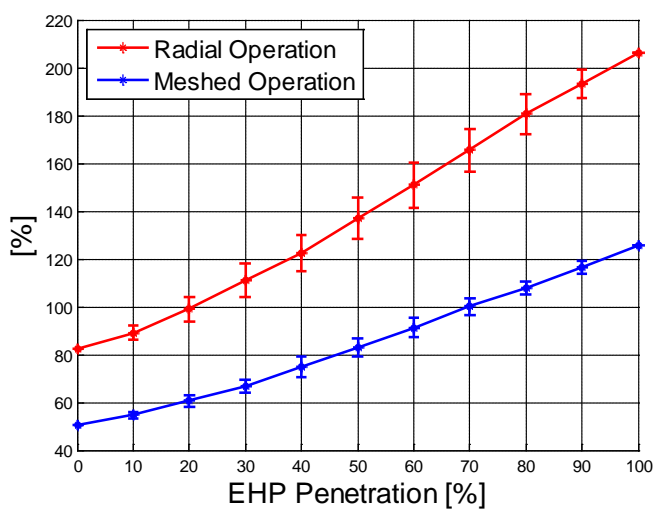

Figure 8. Thermal Problems Feeder 4 - EHP case.

The impact summary of doing loop connection for each feeder with EHP penetration is presented in Table II. This table shows that all of the feeders in the implemented substation present thermal issues earlier than voltage problems for both cases, without and with meshed operation.

Similarly to the PV case, an increase in the hosting capacity of one feeder implies a decrease in that of others. In fact, as it can be observed in Table II, the massive increase in feeder 4 , from $20 \%$ to $70 \%$, produces a reduction in feeder 1 and feeder 3 , from $50 \%$ to $40 \%$ and from no problem to $90 \%$, respectively. These two feeders are the ones directly connected to feeder 4 (Fig. 1), sharing the capacity problems and delaying the occurrence of the first problems in the network. Indeed, if the deployment rate of new residential EHP is the same for each feeder, then the occurrence of the first problems in the network is shifted from $20 \%$ to $40 \%$ of penetration with meshed operation.

TABLE II. VARIATION IN HOSTING CAPACITY - EHP CASE

\begin{tabular}{|c|c|c|c|c|c|c|}
\multicolumn{4}{c|}{ Without Meshed Operation } & \multicolumn{2}{c}{ With Meshed Operation } \\
\hline Feeder & $\begin{array}{c}\text { Voltage } \\
\text { Problems } \\
{[\%]}\end{array}$ & $\begin{array}{c}\text { Thermal } \\
\text { Problems } \\
{[\%]}\end{array}$ & $\begin{array}{c}\text { Host } \\
\text { Capability } \\
{[\%]}\end{array}$ & $\begin{array}{c}\text { Voltage } \\
\text { Problems } \\
{[\%]}\end{array}$ & $\begin{array}{c}\text { Thermal } \\
\text { Problems } \\
{[\%]}\end{array}$ & $\begin{array}{c}\text { Host } \\
\text { Capability } \\
{[\%]}\end{array}$ \\
\hline 1 & none & 50 & $\mathbf{5 0}$ & none & 40 & $\mathbf{4 0}$ \\
\hline 2 & none & none & none & none & none & none \\
\hline 3 & none & none & none & none & 90 & $\mathbf{9 0}$ \\
\hline 4 & 80 & 20 & $\mathbf{2 0}$ & none & 70 & $\mathbf{7 0}$ \\
\hline
\end{tabular}

Therefore, the meshed operation of LV feeders is a powerful short term tool to be used by DNOs to postpone the occurrence of network problems due to high penetrations of future loads, such as EHP or electric vehicles.

\section{SENSITIVITY ANALYSIS}

In the network under analysis, the meshed operation of LV feeders increases the hosting capacity for both the PV and EHP cases. In fact, the hosting PV capacity increases from $40 \%$ to $60 \%$ and the hosting EHP capacity rises from $20 \%$ to $40 \%$. Hence, the problems are deferred in time. These deferrals are obtained in a network where each feeder has exactly the same penetration level of the same technology (PV or EHP), which means that they have the same proportion of low carbon technologies at the same time. This analysis represents a worst case scenario in the sense that there is not any additional headroom, apart from the network characteristics of each feeder (impedance and number of loads) to increase the host capacity. For instance, in the PV case, the voltage problems in feeder 4 start when each feeder has $60 \%$ of penetration when adopting meshed operation. This increase could be bigger if the rest of the feeders have lower penetrations.

To explore the complete range for this potential increase, a sensitivity analysis is carried out for the most ideal scenario for both PV and EHP: only one feeder (feeder 4) with penetration levels ranging from $0 \%$ to $100 \%$, and the rest of the feeders without any PV or EHP.

\section{A. Sensitivity for $P V$}

As expected, the hosting capacity increases considerably when adopting meshed operation of the feeders and with only one of them with PV panels. Fig. 9 shows that the voltage problems appear only at $80 \%$ of penetration. Also, it is possible to observe that the number of customers affected has an important reduction. For example, if every single house has a PV panel (100\% of penetration level), the percentage of customers with voltage problems is about $8 \%$, one tenth of those found with radial operation and $25 \%$ of the base case (every feeder with the same proportion of PV panels).

The meshed operation was also able to reduce the utilization of the main cable, avoiding the $100 \%$ limit for all penetration level as it can be observed in Fig. 10.

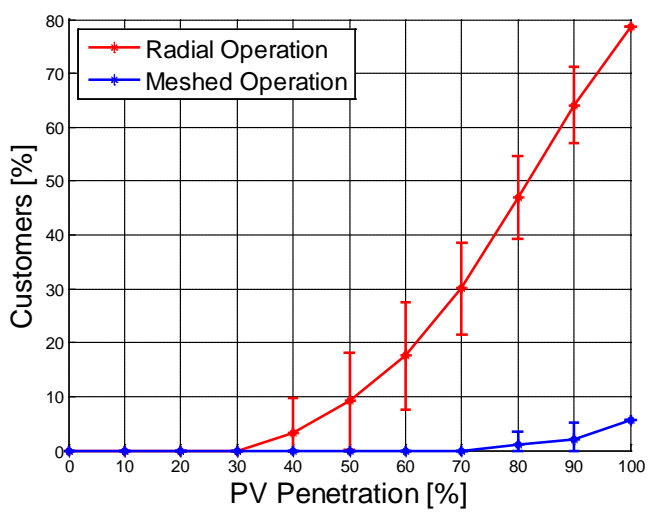

Figure 9. Voltage Problems Feeder 4 - Sensitivity PV case.

It is important to highlight that the rest of the feeders in this network do not reach the maximum capacity limit and they do not present customers with voltage problems. 


\section{Accepted Paper}

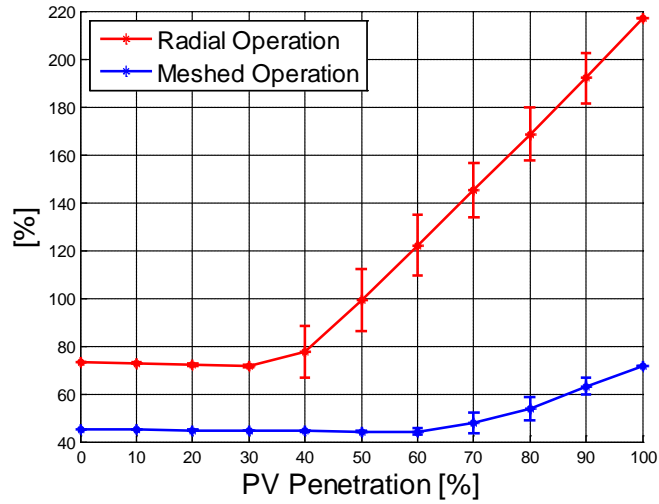

Figure 10. Thermal Problems Feeder 4 - Sensitivity PV case.

From this analysis it is possible to establish some boundaries in terms of the benefits from adopting meshed operation. In this case, the additional hosting capacity is between 20\% (every feeder with PV panels) and 40\% (only one feeder with PV panels).

\section{B. Sensitivity for EHP}

The hosting capacity also increases for the EHP case in comparison with the base case when adopting meshed operation. Fig. 11 indicates that the thermal issues are totally removed. This happens basically because the extra load is shared (supplied) by all of the feeders.

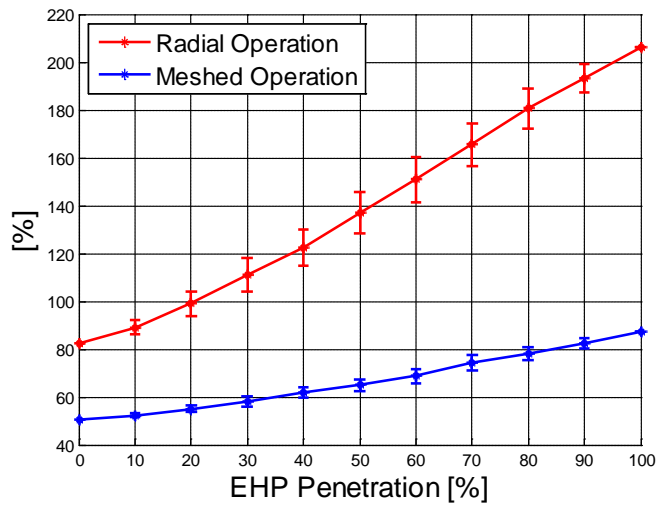

Figure 11. Thermal Problems Feeder 4 - Sensitivity EHP case.

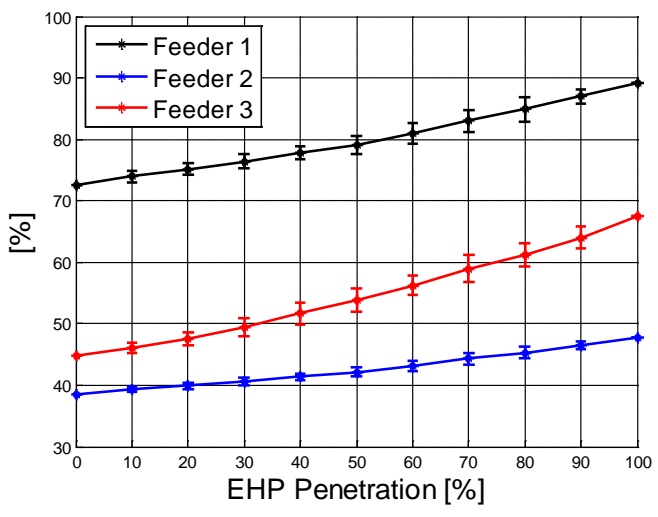

Figure 12. Thermal Problems Feeder 4 - Sensitivity EHP case.
Furthermore, the voltage problems are removed as they were removed previously in the base case, Fig. 7. The feeders without EHP do not reach the maximum capacity limit and they do not present customers with voltage issues. In particular, Fig. 12 shows how the utilization of each feeder evolves with meshed operation when more EHP is aggregated only to feeder 4; indicating how the additional load in feeder 4 is supplied by all of them.

\section{CONCLUSIONS}

The potential benefits from adopting meshed operation of LV feeders was analysed in this work. Two low carbon technologies, PV and EHP, were considered in a real UK LV network. The corresponding gains in hosting capacity were quantified by using a Monte Carlo approach in order to cater for the uncertainties related to demand as well as location and size of PV and EHP. The results show that the meshed operation can significantly increase the hosting capacity of LV networks. Indeed, for the network studied, it was found hosting capacity increases from $40 \%$ to $60 \%$ for the PV case and from $20 \%$ to $40 \%$ for the EHP case in the network developed.

\section{REFERENCES} source heat pumps in a residential area,” Applied Energy, vol. 102, pp. 591-600, Feb. 2013. 